\title{
High dose levomethadyl acetate hydrochloride reduced heroin use in patients dependent on opiates
}

\begin{abstract}
Eissenberg. T, Bigelow GE, Strain EC, et al. Dose-related efficacy of levomethadyl acetate for treatment of opioid dependence. A randomized clinical trial. JAMA 1997 June 25;277:1945-51.
\end{abstract}

\section{Objective}

To assess the clinical efficacy of different doses of levomethadyl acetate hydrochloride (LAAM) in the treatment of patients with opioid dependence.

\section{Design}

Randomised, double blind, controlled trial with 17 week follow up.

\section{Setting}

Outpatient facilities at a medical centre in Maryland, USA.

\section{Patients}

180 patients (mean age 35 y, $61 \%$ men) entering opioid dependency treatment (May 1994 to November 1995). Inclusion criteria included a diagnosis of opioid dependence (Diagnostic and Statistical Manual of Mental Disorders, third edition, revised), an opioid positive urine sample, and no history of serious psychiatric illness.

\section{Intervention}

LAAM was given orally on Mondays, Wednesdays, and Fridays. 62 patients were randomised to the low $(25 / 25 / 35 \mathrm{mg}), 59$ to the medium (50/50/70 mg), and 59 to the high dose (100/100/ $140 \mathrm{mg}$ ) regimen.

\section{Main outcome measures}

The main outcome measures were retention in treatment, the percentage of opioid positive urine samples, 4 weeks of urine verified opiod abstinence, and self reported heroin use.

\section{Main results}

Event rates given relate to the high, medium, and low dose groups, respectively. Retention in treatment at study completion was independent of dose $(59 \%, 66 \%, 55 \%, \mathrm{p}=0.14)$. The intent to treat analysis showed a LAAM dose response effect with the proportion of opioid positive urines $(61 \%, 68 \%, 77 \%$, high $v$ low dose groups, $\mathrm{p}<0.05$ ), and with the proportion of patients who achieved 4 weeks of urine verified opioid abstinence (34\%, 14\%, $11 \%$, high $v$ low $\mathrm{p}<0.01$ ) (table). In the analysis of study completers $(60 \%)$ there was also a dose related reduction in the number of days per month of self reported heroin use (2.5, 4.1, 6.3 , high $v$ low dose groups, $\mathrm{p}<0.05$ ).

\section{Conclusion}

High dose levomethadyl acetate hydrochloride was more effective than low dose levomethadyl acetate hydrochloride in terms of reducing illicit opioid use and in producing sustained periods of heroin abstinence, but no corresponding effect on retention in treatment was detected.

High dose levomethadyl acetate hydrocholride (LAAM) $v$ low and medium dose LAAM*

\begin{tabular}{|c|c|c|c|c|c|}
\hline Outcome & $\begin{array}{l}\text { High dose } \\
\text { (EER) }\end{array}$ & $\begin{array}{l}\text { Medium dose } \\
(C E R)\end{array}$ & $\begin{array}{l}R B I \\
(95 \% C I)\end{array}$ & $\begin{array}{l}A B I \\
|E E R-C E R|\end{array}$ & $\begin{array}{l}\text { NNT } \\
(C I)\end{array}$ \\
\hline \multirow[t]{2}{*}{$\begin{array}{l}4 \text { weeks } \\
\text { abstinence }\end{array}$} & $34 \%$ & $14 \%$ & $\begin{array}{l}150 \% \\
(23 \text { to } 421)\end{array}$ & $20 \%$ & $\begin{array}{l}5 \\
(3 \text { to } 20)\end{array}$ \\
\hline & $\begin{array}{l}\text { High dose } \\
(E E R)\end{array}$ & $\begin{array}{l}\text { Low dose } \\
\text { (CER) }\end{array}$ & $\begin{array}{l}R B I \\
(C I)\end{array}$ & $\begin{array}{l}A B I \\
|E E R-C E R|\end{array}$ & $\begin{array}{l}\text { NNT } \\
(C I)\end{array}$ \\
\hline $\begin{array}{l}4 \text { weeks } \\
\text { abstinence }\end{array}$ & $34 \%$ & $11 \%$ & $\begin{array}{l}200 \% \\
(42 \text { to } 553)\end{array}$ & $23 \%$ & $\begin{array}{l}5 \\
\text { (3 to } 13 \text { ) }\end{array}$ \\
\hline
\end{tabular}

*Abbreviations defined in glossary; RBI, ABI, NNT, and CI calculated from data in article.

Source of funding: US Public Health Service.

For article reprint: Dr R E Johnson, Johns Hopkins University School of Medicine, Department of Psychiatry and Behavioral Sciences, Behavioral Pharmacology Research Unit, 5510 Nathan Shock Drive, Baltimore, MD 21224-6823, USA. Fax +1 8048287862.

\section{Commentary}

LAAM is a synthetic derivative of the long acting opioid methadone, which in clinical practice differs from methadone primarily with respect to its slow onset of action and its long duration of activity. The long half life of LAAM and its active metabolites means that it need only be taken 3 times a week. It takes about 2 weeks to reach steady state levels and should be regulated by supervised consumption. The place of LAAM in clinical practice therefore will be limited to specialised clinics and retail pharmacies which are able to supervise its consumption. In this context, although LAAM is likely to be several times more expensive than methadone and may have higher drop out rates during induction, there are major potential advantages to the patient who would have more time to pursue rehabilitative activities, to the provider in terms of reduced clinical or pharmacy time and staff costs, and to society because of the much reduced potential for diversion.

The study by Eissenberg $e t$ al is important because it is the first to systematically compare the clinical efficacy of different LAAM doses in the treatment of opioid dependence and did so using broad inclusion criteria. The authors used LAAM doses equivalent to 20,40 , and 80 $\mathrm{mg}$ of methadone, and chose these dose concentrations expecting to replicate with LAAM the differential retention rates produced in methadone comparison studies. No effect on retention was found but the more sensitive measure of illicit opioid use did show the predicted pattern. This study also produced a number of other important findings. Firstly, there was a trend for lower retention in the highest dose group during the induction period, probably because of over medication, thus suggesting that body weight should be taken into account in future. Secondly, this is the first double blind study of LAAM maintenance involving women, and shows that sex is not a significant predictor of outcome. Thirdly, there was a large non-specific treatment effect on the number of days the patients reported using cocaine, which was reduced by $63 \%$ in all treatment conditions.

Fergus Law, MB, BS, MRCPsych Psychopharmacology Unit, University of Bristol Bristol, $U K$ 